\title{
Los textos en prosa de Ricardo Molina en Cántico. “Uriel": reflexiones para una poética'
}

\author{
Ricardo Molina's Prose Texts in Cántico. \\ "Uriel”: Critical Approaches for an Art of Poetry \\ JUAN MARIA PRIETO ROLDÁN \\ Universidad de Córdoba \\ España \\ juanmariaprietoroldan@gmail.com
}

(Recibido: 29-II-2OI7; aceptado: I9-OI-2OI8)

Resumen. El propósito de este artículo es explicitar las claves de los textos en prosa de Ricardo Molina en la revista Cántico. La investigación sobre los poetas de «Cántico» en la actualidad exige el establecimiento de unos límites para descubrir la génesis de una posible poética en el grupo y definir su repercusión en la poesía del siglo XX y hasta nuestros días. El intimismo, el esteticismo y el anhelo de perfección, claves en la poética que Molina desvela en los breves ensayos incluidos en la sección «Uriel», pondrán de relieve las influencias y referentes de los poetas "Cántico» y aportarán luz acerca de una posible vinculación de su poesía con Luis de Góngora.

Palabras clave: Molina; poesía contemporánea; esteticismo; perfección; intertextualidad.
Abstract. The purpose of this article is to make explicit the keys of the prose texts of Ricardo Molina in Cántico. Current research about the poets in "Cántico» require setting limits to discover the origins of a possible group poetics and to define their impact in the 20th century up until today. Intimacy, aestheticism and the desire for perfection are key in the poetics that Molina reveals through the short essays from «Uriel», and they highlight the influences and references of the "Cántico» poets, shedding light on possible connection between his poetry and Luis de Góngora.

Keywords: Molina; contemporary poetry; estheticism; perfection; intertextuality.

\footnotetext{
I Para citar este artículo; Prieto Roldán, Juan María (2OI8). Los textos en prosa de Ricardo Molina en Cántico. "Uriel”: reflexiones para una poética. Alabe 18. [www.revistaalabe.com]

DOI: IO.I5645/Alabe20I8.I8.5
} 
En diciembre del año 201 h hemos asistido a la culminación de los actos por el centenario del poeta cordobés Ricardo Molina Tenor (I9I7-I968), codirector de la revista Cántico y una de las voces más reconocibles del panorama de la poesía española de posguerra. Autor de obras como El río de los ángeles, Elegías de Sandua o Corimbo, con la que obtuvo el premio Adonáis en I949, el pontanés se erige en el líder de la propuesta estética con la que el grupo de poetas cordobeses (Ricardo Molina, Juan Bernier, Pablo García Baena, Julio Aumente y Mario López) irrumpe en la poesía de los años 40.

Ricardo Molina es el alma de «Cántico»² y una las figuras más relevantes de la cultura cordobesa contemporánea. Su temprana desaparición, en I968, unida al viraje de su trayectoria a partir del final de la revista-además del silencio creativo de sus compañeros de grupo, que dura casi dos décadas en algunos casos- fueron circunstancias que afectaron al reconocimiento y la repercusión posterior de una influencia y un legado que han sido prácticamente obviados hasta nuestra historia más reciente.

Precisamente tras su temprana desaparición, antes incluso de la vuelta al verso de los poetas de «Cántico» o de la «recuperación» del grupo, que comienza a gestarse a principio de este siglo ${ }^{3}$, son varios los estudiosos que, desde muy pronto, abordan de manera decidida el estudio de la vida, la obra y la personalidad de Ricardo Molina. Entre otros destacan José María de Torre, con trabajos como La obra poética de Ricardo Molina, o Ricardo Molina: biografía de un poeta; Carlos Clementson, no solo con el capítulo que le dedica en su tesis doctoral «La revista "Cántico" y sus poetas», aún hoy inédita, sino con obras como Ricardo Molina, perfil de un poeta o La poesía de Ricardo Molina; o Antonio Rodríguez Jiménez, con la coordinación de las jornadas organizadas en Córdoba en el año 2007, con motivo del 90 aniversario, y de las cuales nació el volumen Ricardo Molina. Conciencia de Cántico; o, más recientemente, la decisiva aportación de Olga Rendón con su obra Los poetas del 27 y el grupo Cántico de Córdoba, donde analiza la correspondencia de Ricardo Molina. Todas estas aportaciones han resultado decisivas en la interpretación y la crítica moliniana hasta nuestros días.

No fue hasta hace once años, en las jornadas organizadas por el Ayuntamiento de Córdoba en 2007 , cuando se adoptó una mirada más actual y profunda sobre su personalidad, un enfoque que tenía en cuenta las múltiples facetas de su actividad: profesor, agitador cultural, traductor, flamencólogo. La diversidad de perspectivas estudiadas desde entonces ha permitido profundizar en el conocimiento de la figura Ricardo Molina y trazar con más rigor el perfil de una personalidad irrepetible.

\footnotetext{
2 A lo largo del ensayo utilizaremos «Cántico» para mencionar al grupo y Cántico para referirnos a la revista.

3 No podemos olvidar la decisiva contribución de Guillermo Carnero con su obra El Grupo «Cántico» de Córdoba (I976), pero también, ya en el presente siglo, el volumen El fervor y la melancolía (2007) de Luis Antonio de Villena. Asimismo, de vital importancia para su recuperación han sido la celebración de homenajes, congresos, exposiciones, o la edición de la poesía completa de Ricardo Molina (2007), Pablo García Baena (2008) y Julio Aumente (2004). Por último, cabe destacar la vigencia de los poetas del grupo hasta la actualidad, por ejemplo con la investidura en el año 20I7 de García Baena como Doctor honoris causa por la Universidad de Córdoba.
} 
Aunque nuestro objeto de estudio está unido inevitablemente a su papel y su liderazgo en Cántico, cabe indagar en su figura y especular sobre la construcción de una concepción poética propia a partir de los testimonios que en sus escritos en prosa. El interés de dichos textos reside -a pesar de que sorprendentemente son escasos los intentos de abordar frontalmente el estudio de su prosa- en que en ellos van apareciendo, en los sucesivos números de la revista, reflexiones y análisis que desvelan las preferencias literarias y estilísticas de los poetas del grupo, incluidas obviamente las del propio Molina.

Así, sin minusvalorar la relevancia de otras aportaciones en prosa de Ricardo Molina -fundamentalmente su libro Función social de la poesía $(\mathrm{I} 97 \mathrm{I})^{4}$ - son dos los documentos que nos pueden llevan a construir con bastante precisión los límites de una poética. En primer lugar, el Diario de Molina, en cuyas páginas es el propio autor el que nos da pistas acerca de sus lecturas e influencias. En él descubrimos que el pontanés asume su liderazgo en el grupo antes de la publicación de la revista. Se comprueba -obviando la decisiva participación de algunos de ellos en «Academia de la gramola», auspiciada por el profesor Carlos López de Rozas- en las primeras tertulias que dinamizan los poetas del grupo. En ellas es Ricardo Molina esa figura clave en torno a la cual se articula el contenido y el desarrollo de las mismas. Ya desde su juventud, su inquietud y sus múltiples lecturas influyen, sin duda, en el camino adoptado por el resto de poetas que frecuentan las tertulias. Descubrimos en muchos testimonios que la personalidad de Ricardo Molina, junto a la de Juan Bernier, tiene un gran peso sobre la trayectoria inicial de sus jóvenes compañeros. En I94O, se instituye la peña «Junio», proyectada en I944 en la «Peña Nómada», que recorrerá distintos bares y tabernas de la ciudad. Las lecturas compartidas, algunas de ellas a partir de traducciones y sugerencias del propio Molina, van configurando el imaginario de los poetas del grupo y, como consecuencia, sus primeros versos.

En r944 y «entre sillones cortijeros y tapices más o menos persas» de «casa Camilo»-genuina y ya desaparecida taberna de la calle Morería- halló temporal cobijo dicha peña, de la que -según «Lynceus»- (se refiere a J. Bernier) tomó el mando «proprio motu» Ricardo Molina y dictatorial, obligó en su primera reunión a escuchar una inmensa traducción de Claudel sobre las siete musas (Torre, I995: 48).

El entusiasmo por la poesía va construyendo el andamiaje que permite elevar los primeros poemas de Ricardo Molina, apenas un veinteañero, y los del resto de poetas «Cántico». En ese sentido, unas palabras del propio Molina en su Diario son muy ilustrativas acerca de ese germen de poética que se atisba en sus primeros versos. De todos es conocido que la propuesta de Molina y de Cántico se situó frente a otras que representaban una línea más oficial y menos preocupada en cuestiones estéticas (Espadaña,

\footnotetext{
${ }^{4}$ Esta obra resultará también de gran valor para adivinar las claves de la cosmovisión moliniana. En ella Molina, a través de una serie de ensayos, reflexiona acerca de la función del poeta en la historia y en la sociedad, utilizando el ejemplo de autores como Baudelaire o Góngora, al que considera paradigma del poeta manierista.
} 
Garcilaso, etc.). Podemos constatar, de hecho, que el poeta trata de influir en la senda escogida por los poetas del grupo: «lentamente induzco a las formas clásicas a aquellos que dispersaron su atención estérilmente en la poesía oficial de España» [I990: 3I].

En segundo lugar, como adelantaba, deberían resultar decisivos para la interpretación moliniana, los textos en prosa que escribe el autor en Cántico situados al final de cada número de la revista, en una sección titulada «Uriel», a veces dentro del apartado «Notas», y más tarde, a partir del tercer número de la segunda etapa, precedidas por el título «Ita et nunc». La revista Cántico, dirigida, como es sabido, por Ricardo Molina, Pablo García Baena y Juan Bernier, se edita en dos etapas: la primera I947-I949, en la que salen a la luz 8 números; y la segunda entre I954-I957, en la que se editan I3 números, dos de ellos dobles. En ella, además de la dirección de la misma, Molina colabora de tres maneras: con los mencionados textos, con poemas (un total de ig se incluyen a lo largo de las dos etapas) y con traducciones. En definitiva, su influencia y liderazgo en la revista serán absolutamente decisivos y lo convertirán en el verdadero factótum de Cántico.

Los textos de «Uriel»y de «Ita et nunc»son, por lo general, no muy extensos. En ellos Ricardo Molina analiza el panorama de la poesía de su tiempo (y de siglos y corrientes no tan cercanos, al menos cronológicamente hablando), para lo cual se centra en obras o autores concretos -algunos contemporáneos, otros no tanto- en cuestiones y conceptos susceptibles de reflexión, desarrollando incluso, como en el «Ita et nunc» del número II-I2 de la segunda etapa de la revista, una muy personal y hasta literaturizada visión del propio acto creativo. Ambas secciones, unidas a otra titulada «Panorama actual de la poesía», contribuyen a valorizar la publicación y aportan el rigor de la crítica literaria a Cántico, una propuesta que ofrece una estética alternativa a la del panorama literario de su tiempo. Asimismo, el hecho de que el poeta reflexione en voz alta, además de situarle como portavoz del grupo, puede dejar entrever las claves que Ricardo Molina prioriza en su concepto de la escritura por lo que, como consecuencia, no debemos estar lejos de una especie de poética propia. Explica Ricardo Molina, en una carta fechada el I8 de enero de I948, la razón de ser de estas prosas y su función en la revista:

«Uriel» no es una sección bibliográfica, sino un diario de experiencias íntimas literarias, que se limitará a tocar brevemente obras, personalidades, problemas de interés permanente o discutidos en el dominio de la poesía. Comprende mi intención: dada la escasez de páginas esta es la única manera de valorizar la revista: tratar sólo cuestiones fundamentales, trascendentes. Así conseguiremos otra cosa: valorar nuestras críticas. Quiero huir por todos los medios de la moda de convertir la página de prosa en un sismógrafo de los movimientos poéticos. Por otra parte no podríamos «registrar» cuanto nos mandan, y, mucho menos, hacer crítica laudatoria (Torre, I995: II4). 
En lugar de realizar un análisis de manera cronológica de los textos de Ricardo Molina, adoptaremos un enfoque más práctico y pedagógico con el que descubrir su diversidad. Así, si se nos permite el reduccionismo, realizaremos una división para reflexionar sobre el sentido de los mismos segmentándolos en varias categorías.

En primer lugar, nos detendremos en aquellos textos de «Uriel» en los que Ricardo Molina se refiere a obras concretas de autores, mayoritariamente, -no siemprecontemporáneos. No nos referimos a los textos incluidos en la sección «Panorama de la poesía» sino a aportaciones que forman parte de la sección «Uriel». Así, en el primer número de la revista encontramos un texto muy significativo, dedicado a Alegría de José Hierro, que obtiene el premio Adonáis de I947. Y es que Molina lo dedica al libro y al autor culpables -en cierto modo- del nacimiento de la revista Cántico ${ }^{5}$, un ejercicio de honradez y prudencia por parte del poeta de Puente Genil. A pesar de que la propuesta poética abanderada por el director de la revista poco coincide con la de José Hierro, el pontanés dedica unas líneas a reconocer el valor de la obra («Este libro de Hierro es con [Subida al Amor] de Bousoño y las [Elegías] de José María Valverde, uno de los más interesantes de la poesía joven» [AA.VV. 2007: I4]). Aunque el poeta sufre en la segunda mitad un arrebato de sinceridad que cuestiona el logro del autor ( «Cómo es posible que Hierro haya caído en el tópico romántico de considerar al dolor camino de la alegría? ¿No se han dicho ya bastante paradojas sobre el tema?» [I4]), este texto es un símbolo de la apertura de la publicación y del poeta que la dirige. En ese mismo sentido, dedica unas brevísimas líneas a la poesía de Gabriel Celaya, en el número 3 de la revista. En dicha ocasión, se refiere el pontanés a la obra Movimientos Elementales, de la que destaca su belleza y su sorprendente lirismo. Al igual que sucedía con José Hierro, no podemos identificar la propuesta de Ricardo Molina con de la Gabriel Celaya. No obstante, el poeta parece apreciar en la poesía del vasco algunos elementos coincidentes con su imaginario poético: «Al principio es la belleza aislada de cada verso la que nos sorprende. (Hay profusión de ellos). Luego, es el poema con su significación original el que gustamos» [46]. La belleza y la vuelta del poema al que fue su fin primigenio son rasgos identitarios enarbolados por la revista y su director, que tienen que ver con la coherencia de su propuesta. La poesía de Gabriel Celaya, de Carlos Bousoño-que goza de un especial reconocimiento por parte de Molina- o de Blas de Otero encuentran su sitio en Cántico, especialmente en esa miscelánea que es la segunda etapa de la revista.

En ese primer número se detiene también Ricardo Molina en el poema «El distraído» de Jorge Guillén. En apenas cuatro líneas, Molina pone de manifiesto en un texto titulado «Asonancias» otra de las preocupaciones estéticas en las que coinciden él y el resto de poetas del grupo. Nos referimos a la musicalidad: «Hay un poema, "El Distraído", de J. Guillén, donde pueden gozarse las más bellas asonancias de nuestra lengua. Como

\footnotetext{
5 Todos los miembros del grupo deciden presentarse al Adonáis de i947. Los títulos presentados fueron los siguientes: Mario López, La tierra confundida; Ricardo Molina, La estrella de ajenjo; Pablo García Baena, Junio, Julio Aumente, Nizam; y Juan Bernier, Aquí en la tierra.
} 
toda la poesía de Guillén, es algo inédito, extraordinario en nuestra Poesía» [I4 $]^{6}$.Ricardo Molina encuentra en Jorge Guillén a uno de sus grandes referentes. Su verso poderoso y audaz, o una rigurosa concepción de la arquitectura del poema en la obra del vallisoletano, le llevan a admirar profundamente al poeta del 27, ese dominio fónico, estructural y lingüístico será clave en una búsqueda creativa en la que encontrará también a poetas como el propio Góngora. En ese sentido es significativa la correspondencia entre ambos. En ese intercambio de cartas, Ricardo Molina, además de hacerle llegar las Elegías de Sandua, apunta el vínculo de esta misma obra con el Cántico de Jorge Guillén: «Pero las Elegías son un libro al margen de mi alma. Concibo éstas cíclicamente como The Leaves of Grasso el Cántico de Guillén» [Rendón, 20I5, II: I65]. De hecho, confiesa el pontanés a Jorge Guillén su admiración por dicha obra: «Si no fuera temerario, yo le diría, afirmaría que entre todos, ninguno más amante de su $C A ́ N T I C O »$ [ı29]. Por ello, no nos extraña que desde los primeros poemas de Molina esté presente una especie de obsesión hímnica, además de por la influencia de las odas claudelianas. El propio Molina escogerá un verso de Mediodía de Jorge Guillén para citarlo al comienzo de su obra Elegías de Sandua. Se trata de un verso cargado de significado, representativo quizás aún hoy de la esencia del grupo y sus poetas: «Por el arroyo claro va la hermosura eterna» [Molina, 2007: I43]. Se trata de un verso que simboliza el anhelo de perfección y belleza que Molina encuentra en el vallisoletano.

En el número 2, Ricardo Molina se detiene en varias obras que le causan una impresión diversa. Así, aparece por primera vez en la revista unos de esos temas constantes en sus reflexiones. El pontanés se refiere a la soledad en la obra de Pedro Pérez Clotet, una soledad que encuentra su espacio en la naturaleza y tiene que ver con la melancolía que desencadena un canto elegíaco en el poeta:

Es la misma soledad del campo andaluz vibrante de rumores, de vientos, de perfumes, o la del pueblecito en un amanecer de septiembre, en el desmayo cenital de julio, en la medianoche de agosto. [...] Fusión de tiempos vividos (azul tiempo de infancia, tiempo rojo de juventud...) que da el tono a ese momento solitario y ancho escogido por el poeta (29).

Dedica Ricardo Molina unas líneas en el siguiente número a valorar la «poética whitmánica»-recordemos la alusión al estadounidense en la carta a Jorge Guillén-y, de nuevo, el poeta se centra en su aportación en la soledad del acto creativo. Molina ya había mencionado en varias ocasiones su admiración temprana por el autor de Hojas de hierba. Veamos las palabras de Molina en este texto:

El poeta es un hombre que vive en su isla y se embriaga en la soledad con la enumeración de lo que le rodea, igual que el Filoctetes de Sófocles que con solo nombrar las rocas, el sol, y

\footnotetext{
${ }^{6}$ Hay otro texto significativo en el número 2 de la revista, titulado «Aliteraciones», dedicado de nuevo al verso, la musicalidad y la expresividad aportada por la aliteración, utilizando el ejemplo de los versos de tres poetas: Louis Aragon, Dámaso Alonso y Luis de Góngora.
} 
la «sonrisa infinita del mar» se siente consolado. La poesía está en los nombres. El nombre hace la cosa, como en los días puros de la creación. El poeta es en oposición al «brodeur» de salón, el que nombra. Nombrar las cosas es sacarlas de la nada. La poesía es una recreación incesante del mundo (46).

En el número 4 de la revista, Ricardo Molina se detiene a analizar en «Uriel» la obra Los poetas ingleses metafísicos (XLIV y XLV), editada en Adonáis. A partir de este texto, introducimos en este trabajo otras de las claves de la poética moliniana, o de los poetas de «Cántico». En la crítica realizada por el pontanés, además de destacar el acierto de este libro y de la propia traducción, Molina reconoce el papel en la historia de estos poetas («marcan una etapa de la poesía inglesa tanto más interesante cuanto más patentes sus relaciones con las tendencias directrices de la actual poesía inglesa» [62]). Esta idea se puede vincular directamente con la propuesta que abandera el director de la revista. En su opinión, estos poetas son el resorte de la posterior revolución del lenguaje que se gesta en la historia de la poesía con la obra de Eliot: «La revolución del lenguaje y del espíritu suscitada en la poesía por T.S. Eliot (revolución tan radical que se ha comparado con el romanticismo) se apoya en la Poética de estos Maestros del XVII, ahora con nuestro Góngora en plena actualidad [62]».

Una vez más emerge la importancia de la tradición clásica en la cosmovisión moliniana. De hecho, no podemos obviar la alusión final de este testimonio, acaso un paralelismo por parte de Ricardo Molina. Parece deducirse que, al igual en el caso de los metafísicos y Eliot, Molina sugiere la importancia de llevar a cabo una ruptura con la poesía oficial -podría ser el caso de los autores del 27, pero sobre todo de los poetas de «Cántico»- iniciando una revolución del lenguaje que tome impulso en otros referentes, en este caso su paisano, Luis de Góngora y Argote.

En el número 5 de Cántico, con la sección «Uriel» incluida en «Notas», dedica una breve reseña a la obra Recados de Gabriela Mistral; además de un análisis más profundo de la obra Las incredulidades de Rafael Montesinos, en la que se fija en el poeta melancólico y desengañado que vuelca su inspiración en ese alarde intimista que puede llegar a ser el poema: «Pero si los motivos humanos (desesperanza, tristeza, decepción) agitan el corazón del poeta - corazón en forma de canción al viento- una consoladora certeza luce (como pera en el limo de la memoria) irradiando su hondo consuelo [78]».

En la segunda etapa de la revista, Ricardo Molina dedica más textos de Ita et nunc a reflexionar sobre el hecho poético que a reseñar obras de autores. No obstante, en un par de ocasiones se prodiga en dicho sentido, aproximándose de nuevo a publicaciones. Así, en el número 6, el pontanés analiza del libro El corazón durante un año, del malagueño José María Souvirón. Entre las características que llaman la atención de nuestro poeta destaca de nuevo su «sabor elegíaco». Molina valora ese intimismo neorromántico que también se le atribuirá a determinados poetas del grupo - no tanto a él mismo-y cuyo origen va de la lectura de los clásicos a la influencia del propio Cernuda. Para Molina, en 
dicha obra «[t]odo contribuye a darnos una impresión neorromántica: el acento confidencial, el todo de media voz, el intenso don de comunicabilidad» [289].

En el penúltimo número de la revista, el de «Cántico» continúa ejerciendo la crítica literaria. Así, en esta edición se aproxima a la obra de otro autor de la época, el cordobés Rafael Porlán. Apunta en él una mirada hacia los clásicos de la tradición española a la vez que su «ímpetu vanguardista». En este texto, señala el discreto reconocimiento de la obra de Porlán, señalando a Góngora como uno de los referentes más ilustres de su cosmovisión poética:

Porlán no alcanzó nunca el rango de gran poeta. Porque la discreción está bien en todo menos en arte. Aquí se confunde con la áurea mediocritas clásica. Y el menos ponderado de los escritores cordobese[s], Don Luis de Góngora, fu[e] el más insigne de todos (434).

Hay en «Uriel» y en «Ita et nunc» otra serie de textos en que Ricardo Molina no toma como pretexto ninguna obra concreta, sino que acude directamente a autores del panorama o la historia de la literatura, ya sea por su relevancia o por la admiración que sus obras le merecen. En los primeros números de Cántico hay varios autores omnipresentes. A continuación de «Uriel», en el apartado «Notas» ${ }^{7}$ escribe Ricardo Molina una columna dedicada a André Gide, que obtuvo precisamente el Premio Nobel en i947. Ya en los primeros testimonios de su Diario, Molina enumera con entusiasmo a varios de los autores que admira: Horacio, Shakespeare, Whitman... y, entre ellos, el propio André Gide. También lo hace en la correspondencia con Jorge Guillén, en una de cuyas cartas confiesa la influencia de los postsimbolistas franceses: Frances Jammes, Paul Claudel y, de nuevo, André Gide. Ricardo Molina traduce los poemas de tres libros esenciales de la poesía gidiana: Les Nourritures Terrestres, Les nouvelles nourritures y Les Cahiers d'André Walter. Asimismo, también conoce las Incidences de Gide, una obra que está entre las lecturas que le ayudan a reflexionar sobre al barroco y el manierismo. En cualquier caso, queda claro el protagonismo de André Gide en este número de Cántico, del que aparecen además ocho poemas traducidos en las páginas centrales.

Como sabemos, además de su papel como codirector, desde los primeros números la aportación de Ricardo Molina va más allá de sus propios poemas. Llegados a este punto, es necesario recordar una significativa aportación del pontanés a Cántico. José María de la Torre en su trabajo «Ricardo Molina: teoría y práctica de la traducción poética», y años después José Reyes de la Rosa, con su ponencia «Ricardo Molina traductor de poesía francesa en la revista Cántico», en el marco del homenaje del año 2007, se habían detenido en el rol de traductor de Ricardo Molina, destacando su extraordinaria influencia en la revista. No son muchas las traducciones que realiza pero son significativa las de determinados autores extranjeros: en la primera etapa de la revista, Paul Claudel, André

\footnotetext{
${ }^{7}$ No nos hemos detenido minuciosamente en el mencionado apartado «Notas» porque no será Molina el único autor que escriba textos. También lo hacen, por ejemplo, Julio Aumente en el número i de Cántico con un texto sobre Milosz, o Juan Bernier, en el número 2, con un texto dedicado a Florbella Espanca.
} 
Gide, Louis Aragon o Charles Peguy; en la segunda etapa de la revista, en el número dedicado a la poesía italiana, traduce a poetas como Ungaretti, Montale, Quasimodo o Pasolini. La propia elección de estos autores es en sí una declaración de intenciones. En ese sentido, el análisis realizado por Reyes pone el foco en tres posibles motivos: el peso de la lengua francesa en la España de la época, el poder y la influencia de la literatura francesa tras la Segunda Guerra Mundial y, por último, la admiración de los poetas del grupo, sobre todo Molina, por algunos poetas franceses con lo que se siente identificado, especialmente Claudel y Gide. Aunque a partir de estos textos en prosa profundizaremos en la influencia de esos y otros autores en la obra de Molina, cabe valorar esta faceta desde una doble vertiente: la difusión de literatura europea de difícil acceso en la época y la modernidad de una aportación que no se encuentra en muchas revistas de la época.

En el texto dedicado a Gide, Ricardo Molina aborda varias claves acerca de la obra y el concepto de poesía del autor francés. El pontanés comienza situando a André Gide entre los autores más importantes de la literatura europea de la época. Se trata de otra figura aislada frente a la línea oficial imperante, un poeta cuya trayectoria no ha sido justamente valorada:

[E]n este instante de su exaltación, su figura, genialmente aislada, se nos antoja el más alto exponente de la cultura europea con todas sus excelencias y defectos. A pesar de la indiscutible grandeza de su obra, pocas tan discutidas como esta (30).

La propuesta de «Cántico», como la de André Gide, cuenta también con detractores. El propio Gide, en el prefacio a Les Norritures terrestres habla del artificio y del olor a cerrado de la literatura de la época. Siente el francés un sentimiento parecido al que experimenta Molina y el resto de poetas del grupo: la poesía se ha convertido en algo distinto a lo que originariamente era, se ha contaminado con reivindicaciones superfluas frente a la eternidad y la comprensión de la realidad que se produce a través de la belleza, por ejemplo aquella que habita en la Naturaleza.

El primer «concepto-clave» que Molina considera necesario conocer de la poesía Gide es el «dénuement», ese «desnudamiento estilístico» a través del cual la obra de Gide encuentra su equilibrio y su esplendor. Ricardo Molina -y los autores de «Cántico»-hallan en las «preocupaciones éticas de Gide» un modelo que les seduce: «Su forma predilecta, el poema en prosa, es particularmente apto para expresar sin violencia, con un arte todo naturalidad, la admirable y ponderada fusión de pensamiento, deseo, exaltación e inquietud característicos» [30].

En este pequeño texto homenaje, Ricardo Molina menciona la que considera «su obra poética culminante», Les Nourritures Terrestres, que califica como «un islote extraordinario en el panorama de los archipiélagos de la actual poesía francesa» [3O]. El desnudo y la belleza del verso de Gide, su «puro hedonismo», su hipersensibilidad, le acercan aún más a los autores de «Cántico». Molina se siente identificado con la naturaleza intimista de Gide, el lugar donde se produce el inevitable encuentro entre lo trascendente y lo material, entre el orden y el caos, entre la represión y el deseo. Señala Josette 
Borrás Dunand cómo Gide resuelve el conflicto «entre les exigences de ses désirs et le besoin de 'rentrer dans l'ordre'» (I984: 4) encontrando una íntima solución estética. El francés elige el mismo camino que escogerá Molina y los poetas «Cántico»: el esteticismo y el intimismo.

[ ; ]No! No he contado aun todas las estrellas del cielo, todas las perlas del mar, todas las [plumas blancas a orillas de los golfos

Ni todos los murmullos de las hojas, ni todas las sonrisas del Alba, ni todas las risas del verano. Y ahora ¿qué diré? ¿Pensáis que porque calle mi boca mi corazón descansa?

(AA.VV., 2007: 27).

En el número 3 de Cántico, Ricardo Molina dedica un texto al también francés Louis Aragon, al que considera «el más significativo poeta de la "generación de la resistencia” $"[46]$. Se trata de un poeta cuya propuesta dista mucho de la de los autores del grupo, y, por supuesto, de la de Molina, pero el pontanés encuentra un resquicio en su obra en el que coinciden ambas miradas. Así, detecta en él, a pesar de que sus preocupaciones están más vinculadas a las circunstancias históricas, una mirada clásica, acaso transparente. Igualmente, en el número 4, encontramos en «Uriel» dos textos sobre dos poetas franceses cuyas trayectorias tienen rasgos que atraen a Molina y que, como Gide -por supuesto en menor medida-, marcan esta primera andadura de la revista: Pierre Emmanuel y Charles Peguy. El primero, otro poeta intimista, en palabras del pontanés, «un poeta del universo interior y como tal, un gran poeta católico» [62]. Sin ser la poesía de Ricardo Molina una poesía religiosa, existe en algunos poetas del grupo un movimiento entre lo religioso y lo pagano que provoca en algunos de sus autores (Bernier, García Baena, etc.) una tensión existencial en el yo lírico. En Les nourritures terrestres de Gide ya encontrábamos un canto de liberación moral en la búsqueda por sus deseos. En la obra de Pierre Emmanuel, también está presente tensión:

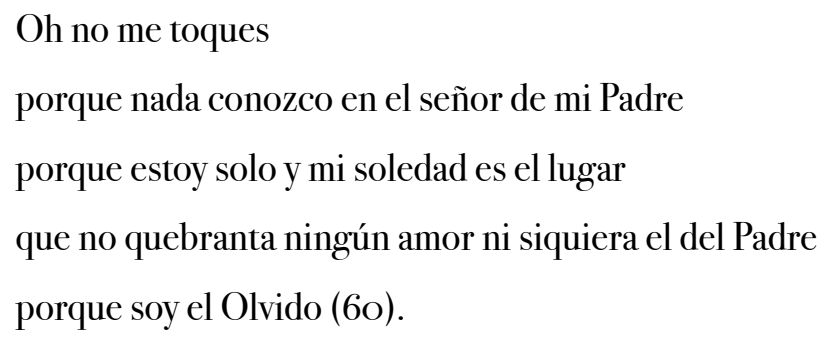

Charles Peguy, un poeta de filiación católica, al que Ricardo Molina califica como «poeta de la pasión», es otro poeta aislado. Esta pasión hace que el pontanés lo compare con los ascetas, dado que «su obra es un tremendo esfuerzo por evocar a Cristo en su auténtica presencia humana» [62]. El pontanés trae a otros dos escritores franceses más a «Uriel» en el número 7 de la revista. Por un lado, a Chateaubriand, al que considera patriarca «no solo de la escuela romántica sino del simbolismo». De otro lado, J. Super- 
vielles, con motivo de una traducción editada por Adonáis, un poeta también ligado a la belleza. Afirma Molina a propósito del francés:

En una época de inquietudes opresoras como la nuestra, lo bello es el supremo consuelo que puede ofrecer el poeta a los hombres [...] la belleza auténtica y cotidiana que nos rodea y que solo puede ser descubierta por la poesía (IIO).

Como vemos, son recurrentes determinadas claves alrededor de las cuales giran las reflexiones de Ricardo Molina, en las que detectamos la coherencia de su propuesta poética.

En el número 6 de la revista no existirá como tal la sección «Uriel». No obstante, Ricardo Molina dedica un extenso monográfico a la poesía de Rafael Laffon [93]. Nos interesa esta aportación no solo por el acercamiento a la obra del mencionado autor sino porque, en la primera parte del texto, Molina realiza una introducción de un gran interés. El pontanés describe un debate que ya se ha insinuado varias veces en esta comunicación y que se sitúa en el epicentro de la identidad del grupo y la revista: la humanización de la poesía y la pérdida de sus valores fundamentales:

El criterio imperante mueve al crítico, viciado por el ambiente, a buscar en el poema algo tan imponderable como la autenticidad, la angustia, la humanidad, sin que pesen apenas en el juicio estimativo la belleza, el lenguaje, la música (93).

Ricardo Molina identifica al sevillano Rafael Laffón como un poeta en cuya obra sí se encuentra esa preocupación («es un ejemplo de arte quintaesenciado donde parecen destilarse las calidades más exquisitas del lenguaje, los más finos matices de nuestra poesía» [93]). ¿Cuáles serán estos matices? En primer lugar, el dominio del lenguaje, la variedad de recursos semánticos y fónicos - claves que ya había valorado en otros autores-. Por otro lado, en esa actitud reside una mirada hacia el pasado que conjuga lo popular y lo conceptista, en directa alusión gongorina.

Sin embargo hay un anhelo que, sobre todos los demás, dirige el impulso creador de Molina -y el resto de autores del grupo-: la perfección. En esa línea uno de los textos más significativos lo encontramos en el número 7 de la revista, bajo el título «Perfección». Molina analiza la importancia de la musicalidad, elemento que ya habíamos situado entre los prioritarios para el pontanés, utilizando el ejemplo de Luis de Góngora. Así, realiza una afirmación lo suficientemente elocuente como para confirmar la influencia de Don Luis en su poética. Dice Molina: «Como siempre es en Góngora donde hallaremos el perfecto canon» [IIo]. En esta ocasión Molina utiliza el famoso verso de don Luis para ejemplificar dicho canon: «infame turba de nocturnas aves», verso de la quinta octava del Polifemo en el que apunta su perfección sinfónica.

Otro canon contemporáneo de perfección que Ricardo Molina tiene muy en cuenta en su obra es el juanramoniano. Así, llama la atención el texto dedicado, en el número 
8 de la primera etapa, a Juan Ramón Jiménez, en el que ensalza la intensidad y la sensibilidad del poeta de Moguer:

No conozco ningún poeta que posea en más alto grado de intensidad lo que P. Valery llamaría "cultura sentimental”. Me refiero a esa virtud de ser "bellamente sensible" [...] Sus versos, un solo verso, nos hacen olvidarlo todo para vivir delicadamente en un mundo de emoción pura y de belleza (I26).

No podemos sino recordar que el gusto de Molina por la imagen en Juan Ramón, es coherente con la mencionada admiración de Molina por los simbolistas. La pureza y la belleza son aspiraciones juanramonianas asumidas con determinación en la poética que va enunciando en «Uriel» el autor de «Cántico». No estamos ante una imagen conceptual, imprecisa, irracional, críptica sino que nos topamos con una realidad que se ofrece a los sentidos, derramándose a la cotidianeidad de un poeta que la enriquece con los matices que el lenguaje y el verso le permiten.

La sección «Ita et nunc» aparecerá por primera vez en el número 3 de la segunda etapa de la revista. En dicha ocasión, Ricardo Molina acude a dos autores de distinta repercusión y época. Molina retrocede al Barroco para poner en valor la deliciosa sensibilidad de Francisco de Rioja, «sumo poeta español de las flores». Además, Con este texto, señala la importancia de la naturaleza -concretamente de las flores- para la intimidad del poeta. El universo simbólico de dicho elemento natural ha estado presente a lo largo de la poesía. Sin embargo, Ricardo Molina advierte en Rioja que este recurso va más allá de la estética para situarse en la ética, el epicureísmo del goce en lo pequeño, en lo sencillo. No podemos evitar reconocer en esta ética al poeta de las Elegías de Sandua.

Más adelante, en el número 7 de esta segunda etapa de la revista, Ricardo Molina realiza un acercamiento a uno de los referentes más significativos de los jóvenes poetas cordobeses pero, sobre todo, de él mismo. Así, dedica el apartado «Ita et nunc» (no una columna sino tres páginas de la revista) a Hombre y Dios de Dámaso Alonso, una figura repleta de significado en la trayectoria de Ricardo Molina. Como vemos en este texto, el pontanés considera a Alonso un referente literario. El interés de Ricardo Molina en la poesía de Dámaso Alonso está quizás en la «progresiva intensificación de los valores humanos» [308] ya que, de ser considerada poco humana, pasa a adquirir cierto apasionamiento, en Hijos de la ira. Sin duda, Hombre y Dios llama la atención, entre otras razones, por su intimismo, que trasciende mucho más allá del propio yo: «Sin embargo, tales experiencias llevan su virtud trascendente a la mayoría.

De nuevo, estamos ante un tipo de poesía que, además de su anhelo esteticista, contiene algo que va más allá de la cáscara. Recoge Molina las palabras del propio Dámaso Alonso. El del 27 sostiene respecto a la poesía: «[N]o puede ser expresión de la realidad inmediata y superficial...sino de la realidad profunda, oculta normalmente en la visa, no intuible sino por medio de la facultad poética y no expresable por nuestro pensamiento lógico [308]». 
El pontanés conoce a la perfección la obra crítica de Dámaso Alonso. De hecho coincide con algunos de los postulados defendidos Alonso, por ejemplo en sus referentes en la construcción del soneto (Lope, Arguijo, Góngora...). De hecho, Ricardo Molina debió manejar los estudios gongorinos de Dámaso Alonso. En cualquier caso, a pesar de este texto, quizás la poesía de Dámaso Alonso no influye profundamente en Molina o al menos no en los poetas de «Cántico». No obstante, la amistad entre ellos es entrañable y duradera. Así, es conocida la valoración y la estima de Molina hacia Alonso, al que considera el «primer gongorista del mundo [...] uno de los poetas más grandes de su generación» [I97I: 250]. Ricardo Molina no solo le dedicará esta sección íntegra al poeta de la Generación del 27, sino que también se detendrá en su Función social de la poesía, en que no pierde la oportunidad de reconocer el valor de la recuperación de Góngora por parte del estudioso y poeta.

Sus numerosos estudios gongorinos rehabilitan al poeta y difunden por el mundo la admiración y la comprensión de su obra...El conocimiento de su poesía ha ayudado a la comprensión de todas las manifestaciones culteranas españolas y de otras, análogas, extranjeras. El que entiende a Góngora entiende también a Quevedo, a Soto de Rojas, a Bocángel, a Gracián, a Milton, a Gryphius, a Marino. Tal ha sido la aportación trascendental de Dámaso Alonso (250).

Hemos de destacar que la amistad de Molina no influye para que Dámaso Alonso se prodigue con colaboraciones en la revista. Sin embargo, Alonso visita Córdoba en innumerables ocasiones, con motivo de sus múltiples investigaciones académicas y gongorinas, con lo que la relación con los autores de «Cántico» se va estrechando. De hecho, gracias a la reciente aportación de Olga Rendón, hemos podido comprobar en la correspondencia entre ambos que Ricardo Molina se erige en el más fiel colaborador de Dámaso Alonso en la elaboración de sus estudios dialectales. Sin embargo, hay un hecho que quizás no se ha explicitado suficientemente: Ricardo Molina colabora de manera callada con Dámaso Alonso en el proceso de documentación de los estudios gongorinos del poeta del 27, que tanta importancia tuvieron en la rehabilitación de Góngora.

Por otro lado, en el número doble IX y X, el homenaje dedicado a Luis Cernuda, escribe Molina un texto titulado «La conciencia trágica del tiempo clave esencial de la poesía de Luis Cernuda». Anteriormente en el número 4 de la segunda etapa de la revista, ya había escrito un texto titulado «Justicia Poética: Luis Cernuda», en el que reclamaba el reconocimiento a la poesía del sevillano. Comienza el pontanés su intervención en el homenaje, aludiendo a una característica de su poesía con la que el propio Molina o los poetas del grupo podrían sentirse identificados, la «fidelidad a sí misma». No obstante, en este texto, que no forma parte de «Uriel» sino que es uno más del homenaje, se refiere a varias claves que coinciden con el anhelo poético moliniano: «ansia de sobria perfección, al dinamismo íntimo de sus semblanzas, a la vivacidad del tránsito del plano real al ideal» $[376]$. 
En este texto, Ricardo Molina alude a la Perfil del aire, obra que considera reveladora de la potente personalidad poética de Luis Cernuda. Es precisamente el sevillano uno de los grandes referentes del intimismo de los poetas de «Cántico». La melancolía de Molina, uno de los poetas elegíacos del grupo, es un elemento que le une a la poética cernudiana, cuya clave, en opinión de Molina, es «la conciencia trágica del tiempo [...]el reiterativo juego antitético entre lo presente y lo ausente» [376-377]. Comenta Ricardo Molina al respecto: «[E]l poeta, sensible al tiempo, siente por todas partes abandono, satúrase de vacío, de desengaño, y, lúcidamente consciente de la nulidad de toda empresa humana, eleva el ocio a la categoría de pura actitud filosófica [377]».

En ese sentido, el poeta de «Cántico» recoge en el texto de Cernuda una cosmovisión poética que identificamos casi absolutamente con la suya propia: «Cuando el sentimiento consciente del tiempo subyuga al poeta con el imperio que a Cernuda, el resultado es necesariamente la elegía. Yo definiría a la elegía como el poema en el que la consciencia del tiempo subordina a otra vivencia [377]».

Estamos ante dos poetas elegíacos - Molina considera toda la obra de Luis Cernuda una «gigantesca y purísima elegía» [377] - en cuyas producciones la melancolía y el desengaño juegan un papel axial. Se refiere Ricardo Molina al poema «Góngora» del sevillano a partir del cual sostiene «En su propia voz, en su propia poesía, halla el poeta consuelo y más aún: fuerza para vivir pese al desengaño, el dolor y la muerte. Lo referido a Góngora puede serlo también a todo auténtico poeta» [379].

La última aportación referida a un autor concreto lo leemos en el número II-I2 de la segunda etapa. Se trata de un texto de tema cordobés titulado «Córdoba y Federico García Lorca». No obstante, el referente de dicha aportación será la obra de un autor al que identificamos de nuevo entre los más admirados por los poetas de «Cántico» y por Molina. Ricardo Molina apunta la presencia de Córdoba en la obra del poeta del 27. En esa breve aproximación, a partir de la «Canción del jinete» de Lorca, el pontanés valora la concepción que el granadino tiene de la ciudad: «Córdoba fue para Lorca algo siempre inasible y remoto: alta, íntima soledad».

Lorca nos pinta una Córdoba negro y plata, que tanto evoca al mármol clásico del último baño del Filósofo, como los alamares y ramos de un traje de luces, la noche y el argento de catafalco o la insomne nostalgia de la medialuna errante en torno a su mezquita (435).

Córdoba como escenario está presente en el intimismo de la poesía del propio Molina, así como en el resto de poetas del grupo. Considera Ricardo Molina cómo en el poema «Córdoba se eleva a símbolo de algo por naturaleza trascendente para todos los hombres y recobra en la poesía de Lorca una altitud trágica universal que no había tenido desde la época de Séneca» [435].

Por último, analizaremos algunos de los textos en los que Ricardo Molina se dedica a reflexionar sobre cuestiones puramente formales. Ya veíamos un adelanto cuando, 
al abordar la musicalidad, confiesa encontrar en Luis de Góngora el canon perfecto ${ }^{8}$. En el primer número de la revista, Ricardo Molina dedica el primer texto de «Uriel» al que considera uno de los poetas más diestros en el ejercicio del soneto, aunque el pontanés no es realmente un sonetista, -sí lo es, por ejemplo, Julio Aumente-. Se trata de Gerardo Diego. En el texto «Gerardo Diego y el soneto», Ricardo Molina considera que es al santanderino «a quien debe principalmente la poesía actual la supervivencia del soneto» (I4). El del 27 representa la cima y el virtuosismo en el que encontrar otro canon de perfección. Su apuesta por el rigor, la armonía y la belleza da vida a un soneto de una honda preocupación arquitectónica. La palabra busca la precisión ya que, en la medida en que el poeta es certero, esta genera belleza e imágenes elocuentes, lo cual redunda en una de las claves de Cántico: la dignificación del lenguaje.

Otro poeta del 27 aparece en el «Uriel» del primer número, en este caso en el texto «Decadencia de la imagen», que reivindica la importancia de la imagen en el poema, frente a la poesía en que pasa a un segundo lugar («La joven poesía española, parece, al contrario, atacada de una pasmosa esterilidad» [I4]). Ricardo Molina alude a un texto que, sin duda, debió conocer a la perfección: nos referimos a la conferencia de La imagen poética de Luis de Góngora. Recoge Molina la siguiente cita de Lorca «la eternidad de un poema depende de la calidad y trabazón de sus imágenes». Otros autores son mencionados en este texto: Juan Ramón, Gabriel Miró, Jorge Guillén, Dámaso Alonso o Vicente Aleixandre, al que acude Molina en el número 4 de la revista, en el que analiza el esplendor de la metáfora aleixandrina, el fuego de su verso, que arde con vigor y esplendor.

Destacaremos, por último, algunos textos aislados donde Ricardo Molina se detiene en analizar determinadas ideas que matizan esa pretendida propuesta poética que alza «Uriel» $\mathrm{e}$ «Ita et nunc». Resulta curioso, por ejemplo, el texto del número 3 de Cánti$c o$ «Realidad y magia», en el que Molina realiza un alegato en torno al realismo en poesía que, según el poeta de «Cántico», encierra una suerte de misterio: «Releo "Miércoles de Ceniza", de Eliot, y me parece que es ahora cuando percibo la clave de este poema donde tan extrañamente se confunden -vivificándose- realidad y misterio» [46]. En el número 8 de la primera etapa, Ricardo Molina escribe dos interesantes textos que nos ayudan a continuar trazando el perfil. Así, en el primero, dedicado -de nuevo- a Juan Ramón Jiménez, ensalza la intensidad y la sensibilidad del poeta de Moguer: «Sus versos, un solo verso, nos hacen olvidarlo todo para vivir delicadamente en un mundo de emoción pura y de belleza» (เ26). En el otro texto desde ese número, titulado «Racionalismo poético», Ricardo Molina reflexiona acerca de la recepción del poema, cuestionando que la actitud con la que un gran número de lectores afrontan la lectura del poema. La frialdad intelectualizante, la búsqueda del concepto y los mecanismos racionales impiden al lector disfrutar del poema. Afirma Ricardo Molina: «La poesía no demuestra ni afirma nada, su persuasión no apela a métodos, ni prevé mecanismos argumentales. Es un simple

\footnotetext{
${ }^{8}$ Esta afirmación tiene unas implicaciones sobre las que cabría profundizar: estamos ante una etiqueta que ha acompañado siempre al grupo «Cántico» y que - esperemos- estudios no muy lejanos resuelvan de manera definitiva.
} 
manifestarse, como el Sol y la música: es la simple evidencia de lo encantador, de lo bello» [ı26]. Y va más allá Ricardo Molina: «La exposición exegética del poema que hace el crítico es siempre una falsificación de la genuina esencia poética, y surge necesariamente a «posteriori». Lo primario es gustar la poesía, paladearla con el espíritu, sin saber casi porqué» [ı26]. Con este texto Molina aborda una cuestión que reside en la misma razón de ser del grupo: la función de la poesía: «La poesía es libada por una misteriosa abeja cuya colmena está muy lejos del entendimiento» [ı26].

No será hasta el número 3 de la segunda etapa cuando Ricardo Molina vuelva a colaborar en la revista con sus textos en prosa. En el primer texto el pontanés comparte su valoración de la celebración del III Congreso de Poesía en Santiago de Compostela, un acontecimiento de un valor especial para el grupo. Nos interesa más el texto, «La poesía comprometida», con el que ahonda en la cuestión sobre la que ya había reflexionado en textos como «Racionalismo poético». Así, Molina cuestiona la poesía engagée, apuntando a la falta de libertad entre los peligros de la poesía comprometida, una opción que puede limitar el «horizonte poético» del poeta, excepto -como menciona el pontanésescritores de la dimensión de Victor Hugo o Pablo Neruda.

El penúltimo número de la revista (XI-XII) contiene un «Ita en nunc» distinto a los que habíamos encontrado hasta entonces. Lo percibimos ya en el primero de los once textos que aporta Molina a esta edición. Así, «La súbita inspiración» es una reflexión entre la crítica literaria y la propia literatura en la que Ricardo Molina narra la propia experiencia de su impulso creador:

Al cruzar perezosamente las Tendillas este mediodía siento de pronto crecer el deseo -(vaga necesidad siempre aplazada) - de escribir. Pero a la vez, una amarguísima clarividencia paralela -tan repentina como aquel deseo- proclama con voz fuerte que el impulso creador y acaso la poesía misma -nuestra fiel sombra, nuestro maltratado amor- sólo son criaturas del vacío, de la carencia, del deseo insatisfecho (434).

En dicho texto, el pontanés aborda directamente alguna de las claves sobre las cuales ya había reflexionado en textos anteriores: el significado de la escritura, las implicaciones del hecho poético, las dificultades de género, etc.

En el cuarto texto, «Scienza nuova, vita nuova» Ricardo Molina continúa en la línea del primero. Estamos ante reflexiones muy personales, acerca de su relación con el mundo y la escritura: «Se han roto cuantos límites mentales contorneaban arbitrariamente lo real. La realidad desborda moldes del pensamiento y entre las cosas puras, naturales, alegres brota en mí nueva ciencia» [435]. Tan personales son estos textos que alguno de ellos tiene un carácter más costumbrista que teórico, como el titulado «Guardia en las Quemadillas (orillas del Guadalquivir, I936)». En ese sentido, la afirmación del siguiente texto, «Ideas y hechos», es toda una revelación: «Me interesa mucho más saber c[ó]mo es una noche de agosto en el Santuario de la Fuensanta, que cualquier teoría filosófica» [436]. Además, los textos «Noche III» «Verdial» o el último «Huertas (Pueblonuevo. Guadiato, I936)». 
En definitiva, una vez realizado este recorrido por los textos de «Uriel» e «Ita et nunc», podríamos especular con la posible construcción de una poética en las reflexiones realizadas por el poeta de Puente Genil. En ella, son varios los rasgos teóricos que podrían definir la estética y la ética de Cántico, pero también de Molina.

En primer lugar, son muchos los números de la revista en los que Ricardo Molina afronta el debate sobre la humanización de la poesía y su pérdida de valores. Para Ricardo Molina la coherencia en poesía consiste en ese anhelo de belleza que no lastra al poeta con preocupaciones históricas o circunstanciales. Molina concibe de hecho la posibilidad de una poesía humana, abierta a la realidad, pero no sometida a ella. El horizonte poético de todo creador no está en el compromiso social, sino en la misma belleza. De otro lado, el pontanés concede un papel significativo al intimismo del poeta, que no solo viene heredado, como bien sabemos, del Modernismo o del 27, sino que entronca a la perfección con la importancia que Molina concede a la soledad del creador, no solo una soledad literal, sino también metafórica, una soledad que tiene que ver con su independencia y libertad. En este aislamiento hay un contexto que acoge al poeta en su experiencia íntima creadora y espiritual. Se trata de la naturaleza, un escenario cómplice para la introspección y la expresión de un yo elegíaco, por lo general, desengañado.

Otro de los rasgos que trata Molina, y que se le achaca sobre todo al resto de poetas del grupo, es el esteticismo. La mencionada humanización deriva, en opinión del autor, en una degeneración del lenguaje poético y su retórica. La recuperación de la esencia de la poesía supone además una vuelta a la dignificación del lenguaje. El refinamiento formal, que va desde la eufonía de los versos hasta el hallazgo de la palabra belleza y precisa, que no redunda en el deseo de construir un verso lujoso, complicado e inaccesible. El objetivo es devolverle al lenguaje lo que le es propio, su natural esplendor, y para ello cada imagen tiene un papel decisivo en el poema. Molina se detiene en muchos textos en valorar la figura de poetas que, valientes, iniciaron de una nueva revolución del lenguaje, como es el caso de Eliot, o el propio Luis de Góngora.

Los textos de «Uriel»e «Ita et nunc» son, como apuntaba Carnero, una especie de «declaración programática», acaso un intento de trazar una poética propia. A pesar de que, como sabemos, Ricardo Molina no refleja en su obra todas y cada una de estas vías, de lo que no cabe duda es de que, en el horizonte de Ricardo Molina se halla una evidente búsqueda de la perfección y sobre todo, una defensa a ultranza de la poesía misma. 


\section{Referencias bibliográficas}

\section{Obras de «Cántico»:}

- AA.VV. (2007). Cántico: hojas de poesía, 1947-1957. Córdoba: Diputación Provincial de Córdoba.

- Bernier, J. (20II). Diario (I9I8-I947), ed. Juan Antonio Bernier. Valencia: Pre-Textos.

- Molina, R. (г97I). Función social de la poesía. Madrid: Fundación Juan March.

- Molina, R. (1990). Diario: (I937-I946), edición, introducción y notas de José María de la Torre. Córdoba: Fundación Cultura y Progreso.

- Molina, R. (2007). Obra poética. 2 volúmenes. Madrid: Visor.

\section{Estudios críticos sobre «Cántico»:}

- Carnero G. (2009). El grupo Cántico de Córdoba. Un episodio clave de la historia de la poesía española de posguerra. Estudio y antología. Madrid: Editorial Nacional.

- Clementson, C. (1979). «La revista "Cántico” y sus poetas», Tesis doctoral, Universidad de Murcia (inédita).

- Clementson, C. (1982). La poesía de Ricardo Molina. Granada, ed. Antonio Ubago. Córdoba: Diputación Provincial de Córdoba.

- Clementson, C. (I986). Ricardo Molina: perfil de un poeta. Córdoba: Monte de Piedad y Caja de Ahorros de Córdoba.

- Palomo, M. del Pilar (2004). Ricardo Molina y la poesía coetánea: Afinidades y discrepancias. En A. Rodríguez Jiménez(ed.), Ricardo Molina, conciencia de Cántico (pp. 37-6o). Sevilla: Renacimiento.

- Rendón Infante, O. (2008). Los poetas de Cántico y la generación del 27. Monteagudo: Revista de literatura española, hispanoamericana y teoría de la literatura, I3, I69-202.

- Rendón Infante, O. (20I5). Los Poetas del 27 y el grupo Cántico de Córdoba. 2 volúmenes. Sevilla: Alegoría. 
- Rodríguez Jiménez, A. (ed.) (20o8). Ricardo Molina, conciencia de Cántico, actas de las jornadas literarias en homenaje a Ricardo Molina organizadas por el Ayuntamiento de Córdoba y celebradas entre los días 6 y 8 de marzo de 2008 para celebrar el 90 aniversario del nacimiento del poeta cordobés. Sevilla: Renacimiento.

- Reyes de la Rosa, J. (2008). Ricardo Molina traductor de poesía francesa en la revista Cántico. En A. Rodríguez Jiménez (ed.). Ricardo Molina, conciencia de Cántico (pp. I37-I60). Sevilla: Renacimiento.

- Torre, J. María de la (I990). Ricardo Molina: Teoría y práctica de la traducción poética. En Actas del III Simposio Internacional de la Asociación Andaluza de Semiótica (pp. I-I6), Granada: Servicio de Publicaciones de la Universidad de Granada.

- Torre, J. María de la (i995). Ricardo Molina: biografía de un poeta. Córdoba: Caja de Ahorros y Monte de Piedad de Córdoba.

- Torre, J. María de la (i997). La obra poética de Ricardo Molina. Córdoba: Diputación de Córdoba.

- Villena, L. Antonio (ed.) (2007). El fervor y la melancolía. Los poetas de «Cántico» y su trayectoria. Sevilla: Fundación José Manuel Lara.

\section{Otras obras de consulta:}

- Borrás Dunand, J. (1984). El tiempo en André Gide. Salamanca: Ediciones Universidad de Salamanca. 